\title{
How Envy and Being Envied Shape Social Hierarchies
}

\author{
Jens Lange $^{1} \&$ Jan Crusius $^{2,3}$ \\ ${ }^{1}$ Department of Differential Psychology and Psychological Assessment, University of \\ Hamburg \\ ${ }^{2}$ Department of Social Psychology, Tilburg University \\ ${ }^{3}$ Social Cognition Center Cologne, University of Cologne
}

Lange, J., \& Crusius, J. (in press). How envy and being envied shape social hierarchies. In S. Protasi (Ed.), The moral psychology of envy. Rowman \& Littlefield.

\author{
Author Notes
}

Jens Lange @https://orcid.org/0000-0002-5375-3247

Jan Crusius @https://orcid.org/0000-0002-9403-6084

We thank Sara Protasi, Felipe Romero, and the other contributors of this volume for valuable feedback.

Correspondence should be addressed to Jens Lange, University of Hamburg, Differential Psychology and Psychological Assessment, Von-Melle-Park 5, 20146 Hamburg, Germany, lange.jens@ outlook.com. 


\section{How Envy and Being Envied Shape Social Hierarchies}

Humans have a strong tendency to form social hierarchies (Magee and Galinsky 2008). They do so quickly and spontaneously. Even when contextual factors minimize the potential for hierarchical structures, they are hardly ever completely absent. This preference for hierarchical organization partly stems from the fact that being at the top of a hierarchy has important advantages. For instance, higher-ranked persons have access to valuable resources, better health, or power over others (e.g., Fournier 2020; Sapolsky 2005; Von Rueden, Gurven, and Kaplan 2011).

Consequently, people are highly vigilant about their social rank. They continuously strive for higher social rank (Anderson, Hildreth, and Howland 2015) and even when they have a high position, their desire to stay at the top remains almost insatiable (Anderson, Hildreth, and Sharps 2020). If humans have a fundamental need for social rank, it follows that humans should be equipped with a set of strong psychological tools allowing them to deal with changes in their position in the hierarchy (Pettit et al. 2016; Sivanathan, Pillutla, and Murnighan 2008). Rising in the hierarchy elicits reactions aimed to reinforce the current course of action, whereas threats to one's position elicit reactions aimed to prevent losing one's rank. Among these strong reactions are emotions. That is, people react emotionally to rank improvements and rank threats, eliciting behaviors aimed to communicate rank improvements to others or averting potentially detrimental consequences of rank threats. Emotions therefore contribute to the regulation of social hierarchies (Steckler and Tracy 2014). One emotion that is at the center of these dynamics, we argue, is envy.

We propose that envy regulates social hierarchies in two ways. First, higher-ranked persons' successes elicit envy in lower-ranked persons. Second, lower-rank persons' envy in turn elicits reactions in higher-ranked persons. Envying and being envied thus occur in a dynamic relationship. To unravel the complexities of this dynamic, we argue in favor of considering the different ways in which social hierarchies form, and how emotions are 
multifaceted experiences. We review evidence for a broad framework that considers these points.

\section{Envy}

Theoretical approaches agree that envy situations include three elements: two persons and an object (e.g., D’Arms 2018; Smith and Kim 2007). One person is advantaged by having the object. The other person is disadvantaged by lacking it. Envy objects include achievements, possessions, or characteristics. Importantly, in all situations, the object is highly self-relevant for the disadvantaged person (e.g., Salovey and Rodin 1984). Put differently, the disadvantaged person experiences envy to the extent that lacking the object reflects negatively on the person's self-evaluation.

Broad evidence indicates that the object's relevance often means higher social rank of the advantaged person (e.g., Crusius and Lange 2017; Fiske 2010; Leahy 2021; see also Rodriguez Mosquera this volume; Romero this volume). Specifically, the object may signal to observers that the person is highly ranked. Hence, envy may often not be elicited by lacking the object but by the advantages associated with it. People envy others primarily for socially valued characteristics such as wealth, attractiveness, status objects, academic success, popularity, or authority (DelPriore, Hill, and Buss 2012). Being advantaged on these dimensions leads to more respect and social influence. Put differently, it leads to a higher social rank. Being disadvantaged on these dimensions, in turn, leads to a lower social rank. Thus, the identity relevance of lacking envy objects may often signal that one's social rank is lower than expected. In line with this notion, changes in people's self-evaluation correspond to changes in their social rank (Mahadevan, Gregg, and Sedikides 2019).

In situations relevant for one's social rank, envy then constitutes a response to inferiority, dealing with this threat to a fundamental need. To do so, envy includes various affective, cognitive, and motivational reactions (e.g., Lange, Weidman, and Crusius 2018; Parrott and Smith 1993). Relatedly, people with a higher desire to attain social rank, such as 
people with higher greed, narcissism, or entitlement, tend to experience envy more intensely (Crusius, Thierhoff, and Lange 2021; Lange, Crusius, and Hagemeyer 2016; Lange, Redford, and Crusius 2019). The goal of the diverse reactions included in envy might thus be to level the rank difference relative to the advantaged person (e.g., Sayers 1969; Van de Ven, Zeelenberg, and Pieters 2009).

According to this perspective, one of envy's social functions is to contribute to the regulation of social hierarchies. It helps persons overcome rank differentials, ensuring that they may eventually gain access to the advantages afforded to those who have higher rank than they have. Notably, this perspective challenges the common view on envy that depicts envy as an immoral emotion with maladaptive consequences for enviers and society. Envy may not be uniformly negative but may even have value such that some of the consequences of envy help enviers improve their outcomes (for a discussion see Lange and Protasi 2021; see also Romero this volume).

The social-functional approach to envy also has implications for persons who exceed another person's rank. If envy aims to level differences in rank, enviers are a threat to a higher-ranked person's position. Accordingly, this person must react to a lower-ranked person's envy to protect their standing and its ensuing advantages. Hence, higher-ranked persons and their enviers could engage in a self-reinforcing cycle of complex emotional interactions.

We propose to analyze this dynamic by dividing it into four steps (Figure 1). First, if envy is a response to other persons' social rank, it will be elicited if a difference in ranks has been established and communicated to others. Second, envy may manifest itself in emotional expressions and behavioral cues communicating itself to others, allowing higher-ranked persons to infer the envy of others. Third, in response to being envied, higher-ranked persons react with either approach or avoidance behavior to deal with this situation. Fourth, these reactions can change the position of higher-ranked persons, starting the circle anew. Jointly, 
these four steps comprehensively outline key elements of the process in which envy and being envied shape social hierarchies.

\section{Step 1: Rank Displays and Envy}

Anthropological and psychological evidence indicates that people attain social rank in at least two ways (e.g., Henrich and Gil-White 2001; Maner and Case 2016). When people pursue a prestige strategy, they gain respect by showing competence, sharing knowledge, and contributing to the group such that others have opportunities to advance. When people pursue a dominance strategy, instead, they intimidate others and elicit fear to secure their position, while they may even lack competence. Notably, despite their differences, both prestige and dominance strategies lead to higher social rank (Cheng et al. 2013). Thus, prestige and dominance strategies differ in their means to reach social rank, yet not in their eventual success.

The two strategies have different implications for lower-ranked persons. In prestige hierarchies, lower-ranked persons can learn how to obtain a higher rank in the long term. In dominance hierarchies, however, lower-ranked persons' future advancement can be obstructed by incompetent superiors. These two different situations have implications for lower-ranked persons' envy toward higher-ranked others. Before turning to these implications, we must consider different ways in which envy can manifest itself.

Specifically, enviers can also accomplish their goal to level the difference between themselves and higher-ranked persons in two ways, namely via benign or malicious envy (e.g., Lange, Weidman, and Crusius 2018; Van de Ven 2016; for a comparison of different perspectives on envy see Crusius et al. 2020). In benign envy, enviers try to level themselves up, that is, improve their relative standing. Benign envy includes higher perceived control to advance (Lange, Crusius, and Hagemeyer 2016; Van de Ven, Zeelenberg, and Pieters 2012), more positive feelings towards envied persons (Van de Ven, Zeelenberg, and Pieters 2009), thoughts about what oneself could have done better (Crusius and Lange in press; see also 
Vendrell Ferran this volume), and a focus on means to improve (Crusius and Lange 2014;

Protasi 2016). Moreover, benign envy fosters improvement behaviors, such as increased effort in achievement tasks (e.g., Lange and Crusius 2015; Van de Ven, Zeelenberg, and Pieters 2011), higher motivation to obtain a better grade (Khan, Bell, and Quratulain 2017), or a higher tendency to purchase products that facilitate productive work (Salerno, Laran, and Janiszewski 2019).

In malicious envy, enviers try to level the envied person down, that is, harm the envied person's social rank. Malicious envy includes higher subjectively perceived undeservingness of envied persons' position (Lange, Crusius, and Hagemeyer 2016; Van de Ven, Zeelenberg, and Pieters 2012), more negative feelings towards them (Van de Ven, Zeelenberg, and Pieters 2009), thoughts about how others should have acted differently (Crusius and Lange in press; see also Vendrell Ferran this volume), and a focus on envied persons (Crusius and Lange 2014; Protasi 2016). Moreover, malicious envy fosters harming behaviors such as choosing more difficult tasks for envied persons (Lange and Crusius 2015), deception in negotiations (Yusainy et al. 2019), or schadenfreude when envied persons fail (Lange, Weidman, and Crusius 2018; Van de Ven et al. 2015).

Therefore, we would expect that the two ways of attaining social rank affect lowerranked persons' envy differently. When higher-ranked persons in prestige hierarchies share competencies and knowledge with lower-ranked persons, lower-ranked persons may experience control to change their situation. These perceptions of control should elicit benign envy. When lower-ranked persons in dominance hierarchies are obstructed by incompetent superiors, they should perceive higher-ranked person's position as undeserved. These subjective perceptions of undeservingness should elicit malicious envy. Prestige and dominance are neither fixed nor exclusive characteristics of social hierarchies. How people perceive them should thus be highly malleable. Hence, when higher-ranked persons display specific signals that lead lower-ranked persons to infer that higher-ranked persons pursue a 
prestige or dominance hierarchy, these displays should elicit benign and malicious envy, respectively.

Evidence is in line with these hypotheses. For instance, higher-ranked persons can signal their higher position by displaying different forms of pride in response to a success (Cheng, Tracy, and Henrich 2010) that, in turn, elicit different forms of envy in lower-ranked persons (Lange and Crusius 2015; see also Lange and Boecker 2019). Specifically, in these studies, participants were or imagined being outperformed by another person in a competition. After winning the competition, the person displayed different forms of pride signaling either prestige or dominance. When higher-ranked persons displayed authentic pride, communicating achievement, accomplishment, and self-worth, observers inferred that higherranked persons pursued a prestige strategy. Accordingly, authentic pride expressed by higherranked persons elicited benign envy in lower-ranked persons. When higher-ranked persons displayed hubristic pride, communicating that they are snobbish, stuck-up, and arrogant, observers inferred that higher-ranked persons pursued a dominance strategy. Accordingly, hubristic pride expressed by higher-ranked persons elicited malicious envy in lower-ranked persons. Thus, higher-ranked persons' displays of social rank shape lower-ranked persons' envy (Crusius and Lange 2017; see also Romero this volume).

\section{Step 2: Cues to Envy}

In competitive situations, lower-ranked persons' envy should become a threat to higher-ranked persons' social rank. Benign envy predicts improved effort in lower-ranked persons (Lange and Crusius 2015; Van de Ven, Zeelenberg, and Pieters 2011) that can eventually translate into higher social rank (Lange, Crusius, and Hagemeyer 2016). Malicious envy predicts harming behavior that can lower higher-ranked persons' standing in the eyes of others (Lange and Boecker 2019). Either way, higher-ranked persons may lose their relative advantage if enviers' behavioral strategies are successful. Given people's fundamental desire 
for social rank (Anderson, Hildreth, and Howland 2015), it is likely that they react to this threat.

Notably, before higher-ranked persons can react to this threat, they need to identify enviers in the first place. To do so, envy must manifest in expressive cues that higher-ranked persons can perceive. Envy could change lower-ranked persons' facial, vocal, or bodily expressions. Typically, emotions distinguish themselves in at least one of these cues (Keltner et al. 2019). Hence, also for envy it may be possible to identify distinct expressive cues.

However, theorizing on envy implies that looking for such expressive cues is a fruitless endeavor. A frequent notion is that enviers disguise their envy (Miceli and Castelfranchi 2007). In fact, they may disguise their envy to such an extent, that they even deny it towards themselves (Smith and Kim 2007). Hence, if envy never manifests in expressive cues, it should be impossible to perceive lower-ranked persons' envy.

Recent evidence puts this earlier research into perspective (Lange et al. 2020).

Dovetailing with the earlier arguments, when unacquainted persons engaged in a competition, successful persons were unable to accurately judge how envious their unsuccessful competitors were. However, when acquainted persons judged each other's inclination to be envious across situations, these judgments were accurate. That is, participants' judgments of acquainted persons' inclination to be envious across situations correlated positively with these persons' self-ratings of these inclinations. This was the case even when controlling for the similarity of the two partners and the possibility that they projected their own (similar) personality on the other person. Thus, with sufficient time or across repeated observations, it may be possible to perceive envy, even if direct evidence for this notion is not yet available.

One reason for the need of time or repeated observations may be that people have to integrate multiple pieces of information to accurately perceive others' envy (e.g., Puranik et al. 2019; Rodriguez Mosquera, Parrott, and Hurtado de Mendoza 2010). Sometimes, a single situation may provide all necessary cues. Often, the necessary cues to others' envy may leak 
only when the persons meet each other in different situations, however. In this respect, envy is different from other emotions that are observable from single, distinct cues.

Research started investigating cues to persons' benign and malicious envy. It suggests that observers infer the specific envy forms from three classes of cues (Lange, Fischer, and Van Kleef in press; see also Puranik et al. 2019). First, a requirement common to benign and malicious envy is that a person is perceived as being worse off than someone else. Second, the situation has painful implications for the person as evidenced by a facial expression. These facial expressions should be different for benign and malicious envy. Specifically, observers should be more likely to infer that a relatively inferior person is benignly envious when a person displays disappointment (which shares a facial expression with sadness). In contrast, observers should be more likely to infer that a relatively inferior person is maliciously envious when this person displays anger. A third cue, specific for benign versus malicious may be whether the person directs attention to either the envied other or the object. An inference of benign envy should be more likely when an inferior person directs attention to the envy object. An inference of malicious envy should be more likely when an inferior person directs attention is to the envied other. Lange et al (in press) presented combinations of these cues in controlled experimental designs or via dedicated photographs. When all three cues were combined in a single situation, facilitating their integrated perception, observers inferred the respective envy form in line with the predictions. Notably, research suggests that enviers indeed display these cues (e.g., Crusius and Lange 2014; Van de Ven, Zeelenberg, and Pieters 2012). However, no research has yet investigated whether enviers display these cues and observers then use the displayed cues accurately to infer enviers' emotion.

\section{Step 3: Reactions to Being Envied}

How higher-ranked persons react to the threat posed by lower-ranked persons is difficult to predict. Early research indicated that people dislike being the target of an upward 
comparison by another person (Exline and Lobel 1999). More recent research indicates that being envied is an ambivalent experience (Duffy, Lee, and Adair 2021; Fileva 2019; Parrott 2017). Specifically, higher-ranked persons react to being envied with both positive and negative feelings; sometimes they like it and sometimes they do not. These feelings may, in turn, spur motivation to approach or avoid enviers, respectively.

A variety of studies documents this ambivalence. For instance, in situations in which they have been envied, people reported that they tried being nice in return, distanced themselves, or deflected attention from themselves (Rodriguez Mosquera, Parrott, and Hurtado de Mendoza 2010). In one study, people imagined that another person is envious and has no control to change the situation (Romani, Grappi, and Bagozzi 2016). Based on the appraisals that shape benign and malicious envy, low control implies that the other person was more likely perceived as maliciously envious. This situation elicited positive feelings when people disliked the envier and negative feelings when people liked the envier. In another study in a work context, being envied predicted both positive feelings as well as anxiety to lose the relationship with the envier (Lee et al. 2018). The positive feelings predicted higher work engagement, which in turn predicted higher job performance. In contrast, anxiety predicted lower work engagement, which in turn predicted lower job performance. In other studies in a work context, being envied predicted efforts to socially reconnect but also predicted higher experienced job tension and desire to leave the organization (Scott et al. 2015) as well as the tendency to hide knowledge from others (Y. Liu, Zhu, and Lam 2020). Finally, when people had an advantage over another person following a random draw, they were more likely to mitigate this person's envy by being more prosocial (Van de Ven, Zeelenberg, and Pieters 2010). This prosocial tendency was more likely to the extent that they perceived the person's envy as malicious.

Thus, being envied causes a variety of reactions in higher-ranked persons. It elicits positive and negative feelings and envied persons sometimes try to get closer to enviers and 
sometimes they distance themselves. Studies document this pattern in remembered situations, the work context, or in experimentally-induced comparison situations. This diversity of methodological approaches underlines that reacting ambivalently to being envied is a robust phenomenon. Until now, there is less theorizing or research predicting which reaction is more likely in a particular situation.

Taking the distinction between benign and malicious envy into account may partly clarify this complexity (see also Parrott 2017), even though no direct evidence supports this proposition. Specifically, we predict that higher-ranked persons who are benignly envied appreciate this situation more. Being benignly envied implies that lower-ranked persons consider higher-ranked persons as role models and try emulating their success. Being in such an exemplary role should bolster higher-ranked persons' confidence and hence elicit positive feelings. The higher appreciation for being benignly envied may subsequently foster approach tendencies, potentially to connect with enviers, to further reinforce self-confidence, or to appease enviers such that enviers cannot threaten the superior position of higher-ranked persons. In contrast, we predict that higher-ranked persons who are maliciously envied dislike this situation. Being maliciously envied implies that lower-ranked persons consider higherranked persons' success as subjectively undeserved and try undermining it. Depending on how effectively enviers can put the harmful intentions into practice, the more afraid higherranked persons will be. The higher dislike for being maliciously envied may subsequently foster avoidance tendencies, potentially to get out of the reach of enviers, isolate them, or to distract oneself from the threat.

One theoretical framework aligns with these ideas (Puranik et al. 2019). It proposes that approach is more likely when the involved parties are in interdependence relationships. Interdependence implies that a groups' success depends on close collaboration. According to the framework, in these contexts, being envied predicts appeasement behaviors. In contrast, when interdependence is low, being envied predicts self-protective behaviors. The framework 
aligns with our predictions because interdependence should be a hallmark of prestige hierarchies, whereas it is less likely to be characteristic for dominance hierarchies. In interdependent groups, given that prestige hierarchies foster benign envy, lower-ranked persons should be more likely to be benignly envious. Higher-ranked persons may then appease enviers, helping them to achieve greater collaborative success in the future and to mitigate enviers' efforts to improve. In contrast, in less interdependent groups, all members must fight for themselves because success is ascribed to individuals and not the team. Relationship-promoting initiatives could even backfire and harm individual success. In such an environment, people might tend to dislike higher-ranked others, eliciting malicious envy. Higher-ranked persons would then need to protect their rank, ideally by avoiding enviers such that they cannot interfere with higher-ranked persons' work.

Two studies further support our arguments. First, in one study, a cooperative as compared to a competitive context led to less feelings of being envied. In this study, according to our opinion, the measure of envy mapped more onto malicious than benign envy (Ye et al. 2021). Second, another study relied on people from Spain as participants and compared them to people from the US (Rodriguez Mosquera, Parrott, and Hurtado de Mendoza 2010; for a detailed discussion of the role of culture in envy see Rodriguez Mosquera this volume). Culturally, Spain is characterized by horizontal collectivism which values higher connectedness and cooperation compared to more individualistic cultures such as the US. In line with our reasoning, Spanish participants expected more benign envy in others than US participants. Thus, situations and cultural contexts that emphasize collaboration are more likely to foster perceptions of being benignly envied, while the same situations also foster approach. In contrast, situations that emphasize competitiveness are more likely to foster perceptions of being maliciously envied, while the same situations also foster avoidance. 
However, our proposition cannot explain all findings. In particular, sometimes higher-ranked persons experience positive feelings when being maliciously envied (Romani, Grappi, and Bagozzi 2016). One interpretation for this finding may be that these positive feelings reflect increased psychological distance between envied persons and enviers. Positive feelings occurred only in situations in which higher-ranked persons disliked enviers. Hence, it may have been pleasurable to see these enviers suffer. This notion is further supported by the finding that higher-ranked persons reported negative feelings toward malicious enviers they liked. These negative feelings may signal empathy towards enviers, a reaction that can soothe the situation.

Another finding that may initially seem at odds with our proposition is that higherranked persons sometimes appease malicious enviers (Van de Ven, Zeelenberg, and Pieters 2010). However, we think this finding is nevertheless compatible with our reasoning. In the study, higher-ranked persons' success resulted from a random draw. Therefore, they may have felt uncomfortable with being advantaged as compared to other persons. Believing that the other persons consider higher-ranked persons' advantage as subjectively undeserved (i.e., is maliciously envious), the higher-ranked persons should be motivated to make it up to the other persons. Appeasement becomes, hence, more likely. Moreover, appeasement behaviors may help higher-ranked persons deal with their own negative feelings that result from being the target of an upward comparison (Exline and Lobel 1999). We expect that when higherranked persons' advantage stems from a competitive interaction, a different pattern will occur. Higher-ranked persons can infer from malicious envy that lower-ranked persons consider their advantage as subjectively undeserved (for a review of such inferences see Lange, Heerdink, and Van Kleef 2021). When higher-ranked persons instead think that they earned their advantage, they may think of lower-ranked persons as disrespectful. Such thoughts should render avoidance more likely. 
Thus, higher-ranked persons who are maliciously envied may appease lower-ranked persons they want to keep close and avoid lower-ranked persons they perceive as distant to begin with. This reasoning implies that the path from being maliciously envied to avoidance is likely moderated. We propose two moderators that determine how the path will unfold: interpersonal closeness and competitiveness. Higher-ranked persons may feel bad for being maliciously envied and appease malicious enviers when they are close to these enviers and when they received non-competitive rewards. In contrast, higher-ranked persons may feel good for being maliciously envied and avoid malicious enviers when they are not close to them and when they received competitive rewards.

Moreover, we expect that also the path from being benignly envied to approach is moderated. When being benignly envied, higher-ranked persons may sometimes fear losing their position. Avoiding benign enviers then assures that these enviers cannot learn from higher-ranked persons or emulate their success. Potentially, the same moderators as for being maliciously envied are important for being benignly envied as well. Specifically, higherranked persons may approach benign enviers when they are close to these enviers and when they earned their success in a competitive context. In contrast, higher-ranked persons may avoid benign enviers when they are not close to these enviers and when they received their success without engaging in a competition.

Even though we argue that the paths from being benignly and maliciously envied to approach and avoidance behaviors, respectively, are moderated, we nevertheless think that they occur most frequently in their direct form. Specifically, we expect that higher-ranked persons react to being benignly envied most frequently with approach and to being maliciously envied with avoidance. This expectation is based on the idea that common situations eliciting benign and malicious envy will steer reactions by higher-ranked persons towards the respective behavior. In most contexts, benign and malicious envy result from competitive encounters, or at least the hierarchy is based on non-random achievements 
(DelPriore, Hill, and Buss 2012). Moreover, prestige hierarchies often foster mutual liking, whereas dominance hierarchies foster mutual disliking (for related arguments see Cheng et al. 2013; Henrich and Gil-White 2001; Lange and Crusius 2015). In combination, these characteristics should foster approach toward benign enviers and avoidance of malicious enviers.

\section{Step 4: Rank Implications of Approach and Avoidance}

Finally, we argue that reactions to being envied further regulate social hierarchies. Approaching benign enviers may reinforce higher-ranked persons' prestige. Approach may include appeasing enviers, but may also increase higher-ranked persons' own effort and performance, as studies document (e.g., Lee et al. 2018). Hence, higher-ranked persons would strengthen their image of being a cooperative, knowledgeable, and successful person. In contrast, avoiding and ignoring malicious enviers may protect higher- ranked persons' dominance without much effort. By reducing contact to malicious enviers, higher-ranked persons lower the risk of becoming a victim of harming behaviors that will challenge or even diminish their intimidating image.

Research at least indirectly supports these predictions. First, previous theorizing predicts that approach fosters mutually supportive relationships between coworkers, whereas avoidance lowers it (Puranik et al. 2019). Hence, approaching benign enviers may further improve social relationships, potentially reinforcing the prestige hierarchy. In contrast, avoiding malicious enviers may further isolate lower-ranked persons, potentially protecting the dominance hierarchy. Second, envied persons were more likely to be ostracized when they were high on neuroticism and low on their need to belong, suggesting that they would not try to reconnect with enviers (F. Liu et al. 2019). From our perspective, trying to socially reconnect with benign enviers may keep relationships with them alive and consequentially reinforce a prestige hierarchy. 
Additional findings also support our proposition. Specifically, expressing positivity as hubristic pride fosters perceptions of dominance (Cheng, Tracy, and Henrich 2010). Hence, expressing positivity towards disliked malicious enviers can reinforce the dominance hierarchy. Moreover, appeasing others by sharing one's failures next to one's successes mitigates their malicious envy and fosters their benign envy (Brooks et al. 2019). Hence, approach following being maliciously envied may protect the dominance hierarchy or even lead to perceptions of prestige when lower-ranked persons start experiencing benign envy. Thus, various studies indicate that reactions by envied persons could further strengthen or protect their social rank.

Interestingly, sustaining or increasing social rank could start the cycle with the four steps anew. Potentially, approach and avoidance initially decrease lower-ranked persons' envy. Nevertheless, the maintained superiority keeps higher-ranked persons in an exposed situation, potentially leading to more envy by others in the future. Thus, envy and being envied shape the social hierarchy continuously.

\section{Summary and Discussion}

In sum, diverse evidence is in line with the conclusion that envy and being envied shape social hierarchies. We analyzed the entire process from rank displays via envy to being envied and corresponding reactions by dividing it into four intertwined steps. Moreover, we argue to consider the two different envy forms - benign and malicious envy - to unravel the dynamic complexities of this process.

Importantly, many of our conclusions are based only on indirect evidence. This point primarily applies to research on being envied, which is still in its infancy. The few studies on this topic rarely distinguished between benign and malicious envy. Accordingly, future research should investigate how higher-ranked persons react to being benignly and maliciously envied and which moderators affect their reactions. Furthermore, categorizing higher-ranked persons' reactions in terms of approach and avoidance may turn out to be too 
broad. Instead, it may be reasonable to develop a more fine-grained classification covering reactions such as appeasement, teasing, or ostracism. Moreover, we deem it important to investigate how these reactions eventually affect the existing hierarchy.

Research on being envied will further benefit from methodological advancement. So far, research on being envied is mostly based on self-report, almost uniformly relying on one particular three-item scale (Vecchio 2005). Two items of this scale measure resentment. Resentment is conceptually distinguishable from envy but, if anything, close to malicious envy (Crusius and Lange 2014; Van de Ven, Zeelenberg, and Pieters 2009; 2012). Therefore, one risk is that research on being envied focused on an emotion other than envy or focused primarily on being maliciously envied. Interestingly, potentially to take this confound into account, sometimes authors replaced the term resentment with envy when using the scale (Lee et al. 2018). The present reasoning implies that future research should develop and validate new scales to measure being benignly and maliciously envied.

Relatedly, it is not certain whether and when self-reports of being envied are valid. In all studies we are aware of, people reported that they are envied. However, the research did not ensure that this impression is accurate. Only in one case did authors complement their main studies with additional data to investigate this question. It suggested that perceptions of being envied may sometimes correlate with actual envy judgments (Lee et al. 2018). Given that, in other studies, people failed to perceive the envy of unacquainted competitors (Lange et al. 2020), we are hesitant to conclude that perceptions of being envied are always accurate. More research is needed on the chronic and situational determinants of people's motivation as well as their ability to show or to hide their envy. Such research should also provide insight into when observers' judgments are more likely to be accurate. At the same time, it is often not important that these perceptions are accurate given that any reaction will mostly depend on higher-ranked persons' subjective perception that they are envied and not necessarily on 
the accuracy of this perception. However, research on being envied has a different meaning when it is about attributions of envy to others as compared to actually being envied.

Ideally, future research would even investigate all four steps simultaneously. One context for such an investigation is a rivalry. A study could follow rivals over repeated interactions in which they establish a hierarchy, measuring lower-ranked rivals' envy and higher-ranked rivals' displays of rank as well as perceptions of being envied and ensuing reactions. For instance, the study could investigate fans of known rivals in team sports in which these teams repeatedly compete. Such a comprehensive study could advance our understanding of the regulatory role of envy in social hierarchies.

\section{Conclusion}

Given their fundamental desire for social rank, people constantly try to advance in social hierarchies or to protect their standing. We argue that one emotion contributing to these efforts is envy. Importantly, envy shapes social hierarchies not only by governing the behavior of those who are worse off. Envy also affects behavior in those who are its target. Specifically, not only do lower-ranked persons react with envy to higher-ranked persons rank displays to change the situation in their favor; higher-ranked persons also try to keep the hierarchy in check by mitigating or distancing themselves from the threat enviers pose. We hope that the present framework facilitates future research by structuring the existing literature and pointing out promising avenues to illuminate how envy and being envied shape social hierarchies. 


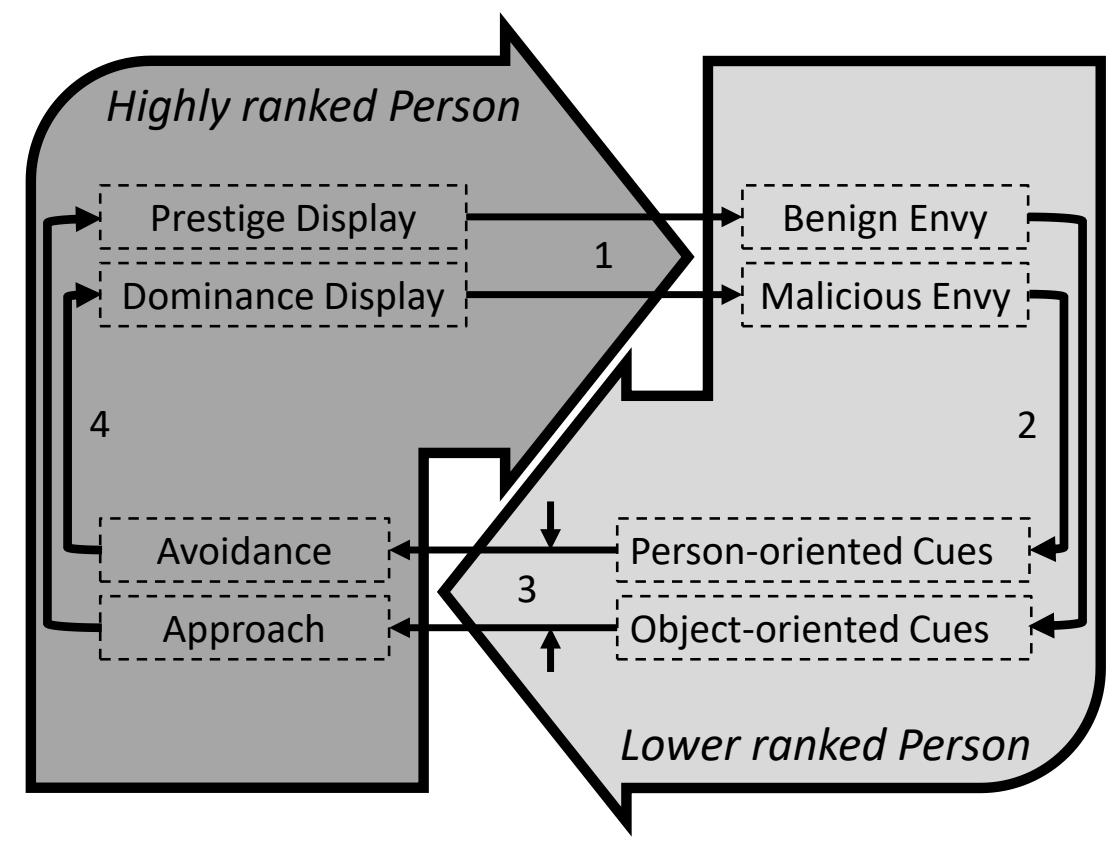

Figure 1. Four steps describing how envy and being envied shape social hierarchies. 


\section{References}

Anderson, Cameron, John Angus D. Hildreth, and Laura Howland. 2015. "Is the Desire for Status a Fundamental Human Motive? A Review of the Empirical Literature.” Psychological Bulletin 141 (3): 574-601. https://doi.org/10.1037/a0038781.

Anderson, Cameron, John Angus D. Hildreth, and Daron L. Sharps. 2020. "The Possession of High Status Strengthens the Status Motive.” Personality and Social Psychology Bulletin 46 (12): 1712-23. https://doi.org/10.1177/0146167220937544.

Brooks, Alison Wood, Karen Huang, Nicole Abi-Esber, Ryan W. Buell, Laura Huang, and Brian Hall. 2019. "Mitigating Malicious Envy: Why Successful Individuals Should Reveal Their Failures.” Journal of Experimental Psychology: General 148 (4): 66787. https://doi.org/10.1037/xge0000538.

Cheng, Joey T., Jessica L. Tracy, Tom Foulsham, Alan Kingstone, and Joseph Henrich. 2013. "Two Ways to the Top: Evidence That Dominance and Prestige Are Distinct yet Viable Avenues to Social Rank and Influence.” Journal of Personality and Social Psychology 104 (1): 103-25. https://doi.org/10.1037/a0030398.

Cheng, Joey T., Jessica L. Tracy, and Joseph Henrich. 2010. "Pride, Personality, and the Evolutionary Foundations of Human Social Status.” Evolution and Human Behavior 31 (5): 334-47. https://doi.org/10.1016/j.evolhumbehav.2010.02.004.

Crusius, Jan, Manuel F. Gonzalez, Jens Lange, and Yochi Cohen-Charash. 2020. "Envy: An Adversarial Review and Comparison of Two Competing Views.” Emotion Review 12 (1): 3-21. https://doi.org/10.1177/1754073919873131.

Crusius, Jan, and Jens Lange. 2014. "What Catches the Envious Eye? Attentional Biases within Malicious and Benign Envy.” Journal of Experimental Social Psychology 55 (November): 1-11. https://doi.org/10.1016/j.jesp.2014.05.007.

_ 2017. "How Do People Respond to Threatened Social Status? Moderators of Benign versus Malicious Envy.” In Envy at Work and in Organizations: Research, Theory, 
and Applications, edited by R. H. Smith, U. Merlone, and M. K. Duffy, 85-110. New York, NY: Oxford University Press.

— in press. "Counterfactual Thoughts Distinguish Benign and Malicious Envy." Emotion.

Crusius, Jan, Josephine Thierhoff, and Jens Lange. 2021. “Dispositional Greed Predicts Benign and Malicious Envy." Personality and Individual Differences 168 (January): 110361. https://doi.org/10.1016/j.paid.2020.110361.

D’Arms, Justin. 2018. “Envy.” In Stanford Encyclopedia of Philosophy, edited by E. N. Zalta. https://plato.stanford.edu/archives/spr2018/entries/envy/.

DelPriore, Danielle J., Sarah E. Hill, and David M. Buss. 2012. “Envy: Functional Specificity and Sex-Differentiated Design Features." Personality and Individual Differences 53 (3): 317-22. https://doi.org/10.1016/j.paid.2012.03.029.

Duffy, Michelle K., KiYoung Lee, and Elizabeth A. Adair. 2021. "Workplace Envy.” Annual Review of Organizational Psychology and Organizational Behavior 8 (1): 19-44. https://doi.org/10.1146/annurev-orgpsych-012420-055746.

Exline, Julie Juola, and Marci Lobel. 1999. “The Perils of Outperformance: Sensitivity about Being the Target of a Threatening Upward Comparison.” Psychological Bulletin 125 (3): 307-37. https://doi.org/10.1037/0033-2909.125.3.307.

Fileva, Iskra. 2019. “Envy’s Non-Innocent Victims.” Journal of Philosophy of Emotion 1 (1): 1-22. https://doi.org/10.33497/jpe.v1i1.25.

Fiske, Susan T. 2010. "Envy up, Scorn down: How Comparison Divides Us.” American Psychologist 65 (8): 698-706. https://doi.org/10.1037/0003-066X.65.8.698.

Fournier, Marc A. 2020. "Dimensions of Human Hierarchy as Determinants of Health and Happiness." Current Opinion in Psychology 33: 110-14. https://doi.org/10.1016/j.copsyc.2019.07.014. 
Henrich, Joseph, and Francisco J Gil-White. 2001. "The Evolution of Prestige: Freely Conferred Deference as a Mechanism for Enhancing the Benefits of Cultural Transmission." Evolution and Human Behavior 22 (3): 165-96. https://doi.org/10.1016/S1090-5138(00)00071-4.

Keltner, Dacher, Disa Sauter, Jessica Tracy, and Alan Cowen. 2019. "Emotional Expression: Advances in Basic Emotion Theory." Journal of Nonverbal Behavior 43 (2): 133-60. https://doi.org/10.1007/s10919-019-00293-3.

Khan, Abdul Karim, Chris M. Bell, and Samina Quratulain. 2017. “The Two Faces of Envy: Perceived Opportunity to Perform as a Moderator of Envy Manifestation.” Personnel Review 46 (3): 490-511. https://doi.org/10.1108/PR-12-2014-0279.

Lange, Jens, and Lea Boecker. 2019. "Schadenfreude as Social-Functional Dominance Regulator.”Emotion 19 (3): 489-502. https://doi.org/10.1037/emo0000454.

Lange, Jens, and Jan Crusius. 2015. "The Tango of Two Deadly Sins: The Social-Functional Relation of Envy and Pride.” Journal of Personality and Social Psychology 109 (3): 453-72. https://doi.org/10.1037/pspi0000026.

Lange, Jens, Jan Crusius, and Birk Hagemeyer. 2016. “The Evil Queen’s Dilemma: Linking Narcissistic Admiration and Rivalry to Benign and Malicious Envy." European Journal of Personality 30 (2): 168-88. https://doi.org/10.1002/per.2047.

Lange, Jens, Agneta H. Fischer, and Gerben A. Van Kleef. in press. “'You're Just Envious': Inferring Benign and Malicious Envy from Facial Expressions and Contextual Information.” Emotion.

Lange, Jens, Birk Hagemeyer, Thomas Lösch, and Katrin Rentzsch. 2020. “Accuracy and Bias in the Social Perception of Envy.” Emotion 20 (8): 1399-1410. https://doi.org/10.1037/emo0000652.

Lange, Jens, Marc W. Heerdink, and Gerben A. Van Kleef. 2021. "Reading Emotions, Reading People: Emotion Perception and Inferences Drawn from Perceived 
Emotions." Current Opinion in Psychology, June.

https://doi.org/10.1016/j.copsyc.2021.06.008.

Lange, Jens, and Sara Protasi. 2021. "An Interdisciplinary Perspective on the Value of Envy."

Review of Philosophy and Psychology, April. https://doi.org/10.1007/s13164-02100548-3.

Lange, Jens, Liz Redford, and Jan Crusius. 2019. “A Status-Seeking Account of

Psychological Entitlement.” Personality and Social Psychology Bulletin 45 (7): 111328. https://doi.org/10.1177/0146167218808501.

Lange, Jens, Aaron C. Weidman, and Jan Crusius. 2018. "The Painful Duality of Envy:

Evidence for an Integrative Theory and a Meta-Analysis on the Relation of Envy and Schadenfreude.” Journal of Personality and Social Psychology 114 (4): 572-98. https://doi.org/10.1037/pspi0000118.

Leahy, Robert L. 2021. "Cognitive-Behavioral Therapy for Envy.” Cognitive Therapy and Research 45: 418-27. https://doi.org/10.1007/s10608-020-10135-y.

Lee, KiYoung, Michelle K. Duffy, Kristin L. Scott, and Michaéla C. Schippers. 2018. "The Experience of Being Envied at Work: How Being Envied Shapes Employee Feelings and Motivation.” Personnel Psychology 71 (2): 181-200. https://doi.org/10.1111/peps.12251.

Liu, Fang, Dege Liu, Juncheng Zhang, and Jingxing Ma. 2019. “The Relationship between Being Envied and Workplace Ostracism: The Moderating Role of Neuroticism and the Need to Belong." Personality and Individual Differences 147 (September): 223-28. https://doi.org/10.1016/j.paid.2019.04.040.

Liu, Yan, Julie N.Y. Zhu, and Long W. Lam. 2020. “Obligations and Feeling Envied: A Study of Workplace Status and Knowledge Hiding." Journal of Managerial Psychology 35 (5): 347-59. https://doi.org/10.1108/JMP-05-2019-0276. 
Magee, Joe C., and Adam D. Galinsky. 2008. "Social Hierarchy: The Self-reinforcing Nature of Power and Status.” The Academy of Management Annals 2 (1): 351-98. https://doi.org/10.1080/19416520802211628.

Mahadevan, Nikhila, Aiden P. Gregg, and Constantine Sedikides. 2019. "Is Self-Regard a Sociometer or a Hierometer? Self-Esteem Tracks Status and Inclusion, Narcissism Tracks Status.”Journal of Personality and Social Psychology 116 (3): 444-66. https://doi.org/10.1037/pspp0000189.

Maner, Jon K., and Charleen R. Case. 2016. “Dominance and Prestige: Dual Strategies for Navigating Social Hierarchies.” In Advances in Experimental Social Psychology, edited by James M. Olson and Mark P. Zanna, 54:129-80. Elsevier. http://linkinghub.elsevier.com/retrieve/pii/S0065260116300144.

Miceli, Maria, and Cristiano Castelfranchi. 2007. "The Envious Mind.” Cognition \& Emotion 21 (3): 449-79. https://doi.org/10.1080/02699930600814735.

Parrott, W. G. 2017. “The Benefits and Threats from Being Envied in Organizations.” In Envy at Work and in Organizations, edited by R. H. Smith, U. Merlone, and M. K. Duffy, 455-74. New York: Oxford University Press.

Parrott, W. G., and R. H. Smith. 1993. "Distinguishing the Experiences of Envy and Jealousy.” Journal of Personality and Social Psychology 64 (6): 906-20. https://doi.org/10.1037/0022-3514.64.6.906.

Pettit, Nathan C., Sarah P. Doyle, Robert B. Lount, and Christopher To. 2016. "Cheating to Get Ahead or to Avoid Falling behind? The Effect of Potential Negative versus Positive Status Change on Unethical Behavior." Organizational Behavior and Human Decision Processes 137 (November): 172-83. https://doi.org/10.1016/j.obhdp.2016.09.005.

Protasi, Sara. 2016. "Varieties of Envy." Philosophical Psychology 29 (4): 535-49. https://doi.org/10.1080/09515089.2015.1115475. 
Puranik, Harshad, Joel Koopman, Heather C. Vough, and Daniel L. Gamache. 2019. “They Want What I've Got (I Think): The Causes and Consequences of Attributing Coworker Behavior to Envy." Academy of Management Review 44 (2): 424-49. https://doi.org/10.5465/amr.2016.0191.

Rodriguez Mosquera, Patricia M. this volume. "A Sociocultural Perspective on Envy: On Covetous Desire, the Evil Eye, and the Social Regulation of Equality." In The Moral Psychology of Envy, edited by Sara Protasi. Rowman \& Littlefield.

Rodriguez Mosquera, Patricia M., W. Gerrod Parrott, and Alejandra Hurtado de Mendoza. 2010. "I Fear Your Envy, I Rejoice in Your Coveting: On the Ambivalent Experience of Being Envied by Others.” Journal of Personality and Social Psychology 99 (5): 842-54. https://doi.org/10.1037/a0020965.

Romani, Simona, Silvia Grappi, and Richard P. Bagozzi. 2016. "The Bittersweet Experience of Being Envied in a Consumption Context." European Journal of Marketing 50 (7/8): 1239-62. https://doi.org/10.1108/EJM-03-2015-0133.

Romero, F. this volume. “On the Epistemic Effects of Envy in Academia.” In The Moral Psychology of Envy, edited by Sara Protasi. Rowman \& Littlefield.

Salerno, Anthony, Juliano Laran, and Chris Janiszewski. 2019. "The Bad Can Be Good: When Benign and Malicious Envy Motivate Goal Pursuit.” Journal of Consumer Research 46 (2): 388-405. https://doi.org/10.1093/jcr/ucy077.

Salovey, Peter, and Judith Rodin. 1984. "Some Antecedents and Consequences of SocialComparison Jealousy.” Journal of Personality and Social Psychology 47 (4): 780-92. https://doi.org/10.1037/0022-3514.47.4.780.

Sapolsky, R. M. 2005. “The Influence of Social Hierarchy on Primate Health.” Science 308 (5722): 648-52. https://doi.org/10.1126/science.1106477.

Sayers, D.L. 1969. The Other Six Deadly Sins. New York: Harcourt, Brace \& World. 
Scott, Kristin L., Stefan Tams, Michaéla C. Schippers, and KiYoung Lee. 2015. “Opening the Black Box: Why and When Workplace Exclusion Affects Social Reconnection Behaviour, Health, and Attitudes.” European Journal of Work and Organizational Psychology 24 (2): 239-55. https://doi.org/10.1080/1359432X.2014.894978.

Sivanathan, Niro, Madan M. Pillutla, and J. Keith Murnighan. 2008. "Power Gained, Power Lost.” Organizational Behavior and Human Decision Processes 105 (2): 135-46. https://doi.org/10.1016/j.obhdp.2007.10.003.

Smith, R. H., and Sung Hee Kim. 2007. “Comprehending Envy.” Psychological Bulletin 133 (1): 46-64. https://doi.org/10.1037/0033-2909.133.1.46.

Steckler, Connor M., and Jessica L. Tracy. 2014. “The Emotional Underpinnings of Social Status.” In The Psychology of Social Status, edited by Joey T. Cheng, Jessica L. Tracy, and Cameron Anderson, 201-24. New York: Springer.

Van de Ven, Niels. 2016. "Envy and Its Consequences: Why It Is Useful to Distinguish between Benign and Malicious Envy." Social and Personality Psychology Compass 10 (6): 337-49. https://doi.org/10.1111/spc3.12253.

Van de Ven, Niels, Charles E. Hoogland, Richard H. Smith, Wilco W. van Dijk, Seger M. Breugelmans, and Marcel Zeelenberg. 2015. "When Envy Leads to Schadenfreude." Cognition and Emotion 29 (6): 1007-25. https://doi.org/10.1080/02699931.2014.961903.

Van de Ven, Niels, M. Zeelenberg, and R. Pieters. 2011. "Why Envy Outperforms Admiration." Personality and Social Psychology Bulletin 37 (6): 784-95. https://doi.org/10.1177/0146167211400421.

Van de Ven, Niels, Marcel Zeelenberg, and Rik Pieters. 2009. "Leveling up and down: The Experiences of Benign and Malicious Envy.” Emotion 9 (3): 419-29. https://doi.org/10.1037/a0015669. 
- 2010. "Warding off the Evil Eye: When the Fear of Being Envied Increases Prosocial Behavior." Psychological Science 21 (11): 1671-77. https://doi.org/10.1177/0956797610385352.

—. 2012. "Appraisal Patterns of Envy and Related Emotions." Motivation and Emotion 36 (2): 195-204. https://doi.org/10.1007/s11031-011-9235-8.

Vecchio, Robert. 2005. "Explorations in Employee Envy: Feeling Envious and Feeling Envied." Cognition \& Emotion 19 (1): 69-81. https://doi.org/10.1080/02699930441000148.

Vendrell Ferran, I. this volume. “'I Could Have Been You': Existential Envy and the Self.” In The Moral Psychology of Envy, edited by Sara Protasi. Rowman \& Littlefield.

Von Rueden, C., M. Gurven, and H. Kaplan. 2011. "Why Do Men Seek Status? Fitness Payoffs to Dominance and Prestige." Proceedings of the Royal Society B: Biological Sciences 278 (1715): 2223-32. https://doi.org/10.1098/rspb.2010.2145.

Ye, Yijiao, Yijing Lyu, Ho Kwong Kwan, Xingwen Chen, and Xuan-Mei Cheng. 2021. "The Antecedents and Consequences of Being Envied by Coworkers: An Investigation from the Victim Perspective.” International Journal of Hospitality Management 94 (April): 102751. https://doi.org/10.1016/j.ijhm.2020.102751.

Yusainy, Cleoputri, Ziadatul Hikmiah, Cathy Sofhieanty, and Muhammad Ibrahim. 2019. "Deception in Negotiation: The Predicting Roles of Envy and Individual Differences." ANIMA Indonesian Psychological Journal 33 (4): 203-12. https://doi.org/10.24123/aipj.v33i4.1794. 